\title{
The Dimensional Structure of the Schizotypal Personality Questionnaire Adapted for Children (SPQ-C-D): An Evaluation in the Dutch Population and a Comparison to Adult Populations
}

\author{
Sophie van Rijn, ${ }^{1,2}$ Pieter Kroonenberg, ${ }^{3}$ Tim Ziermans, ${ }^{1,2}$ and Hanna Swaab ${ }^{1,2}$ \\ ${ }^{1}$ Clinical Child and Adolescent Studies, Leiden University, Wassenaarseweg 52, 2333 AK Leiden, Netherlands \\ ${ }^{2}$ Leiden Institute for Brain and Cognition, P.O. Box 9600, 2300 RC Leiden, Netherlands \\ ${ }^{3}$ Family Studies, Leiden University, Wassenaarseweg 52, 2333 AK Leiden, Netherlands \\ Correspondence should be addressed to Sophie van Rijn; srijn@fsw.leidenuniv.nl
}

Received 16 September 2014; Accepted 21 January 2015

Academic Editor: Takahiro Nemoto

Copyright (C) 2015 Sophie van Rijn et al. This is an open access article distributed under the Creative Commons Attribution License, which permits unrestricted use, distribution, and reproduction in any medium, provided the original work is properly cited.

\begin{abstract}
The increasing interest in dimensional approaches towards schizophrenia spectrum pathology calls for instruments that can be used to study developmental markers conveying risk for psychopathology prior to onset of the disorder. In this study we evaluated the Dutch child version (SPQ-C-D) of the Schizotypal Personality Questionnaire (SPQ) developed by Raine, in terms of reliability and factorial structure in comparison to SPQ data from two studies with adults. The 74-item SPQ-C-D was completed by 219 children and adolescents aged 9 to 18 years. Internal consistency was assessed and the factorial structure was analyzed using principal component analysis (PCA) and confirmatory factor analysis. Results showed that most of the subscales had high Cronbach's alphas, indicating good internal consistency. PCA resulted in three components, similar to the adult studies: Cognitive-Perceptual, Interpersonal, and Disorganization. The pattern of individual subscales loading on each of the components was identical to the original Raine study, except for one additional subscale loading on the Disorganization component. In addition, forcing Raine's factorial structure on our data with confirmatory factor analysis resulted in an overall adequate model fit. In conclusion, the SPQC-D appears to be a suitable dimensional measure of schizotypal traits in populations aged 9 to 18 years.
\end{abstract}

\section{Introduction}

The introduction of the fifth edition of the Diagnostic Statistical Manual of Mental Disorders (DMS-5) and the Research Domain Criteria (RDoC) project constitutes a major shift in schizophrenia research, which urges the use of dimensional approaches of psychotic-like phenomena. Phenomena that are part of the clinical phenotype of schizophrenia spectrum disorders are quantitatively distributed along a continuum, rather than or in addition to being categorical disease entities $[1,2]$. Such subclinical experiences which do not meet the clinical threshold or criteria for schizophrenia spectrum disorders are known as "psychosis proneness," "at-risk mental states," or "schizotypal personality traits" [3-7]. In this paper we will refer to these characteristics as "schizotypal traits," which can be measured using self-report questionnaires, such as the Schizotypal Personality Questionnaire (SPQ), which exists as an extended, 74-item version [8] and an abbreviated 22-item version, that is, the SPQ-B [9].

Most studies on schizotypal traits have concentrated on adult samples, specifically on individuals with schizophrenia spectrum disorder or schizotypal disorder and their relatives. However, there is compelling evidence suggesting that, already many years before the onset of the illness, deviant behavioural and cognitive development is present in children who are later diagnosed with schizotypal personality disorder or schizophrenia spectrum disorders [10-12]. It is important to be able to measure schizotypal traits, preferably in childhood and adolescence, as it is necessary to focus on development before and during adolescence in order to gain insight into the processes of aberrant (neuro-)development that indicates risk for severe outcome in adulthood [13]. 
Self-report questionnaires assessing schizotypal traits have good long-term predictive validity as empirical evidence shows that individuals with high scores on self-reports of schizotypal traits are at increased risk for later development of schizophrenia spectrum disorders in both community [1417] and clinical samples $[18,19]$. The use of psychometric inventories for assessing levels of schizotypal traits (the socalled psychometric high-risk method) has advanced considerably in the last three decades and is considered a feasible, valid, inexpensive, and noninvasive technique for identifying schizotypal traits [20].

Scales measuring schizotypal traits have been shown to have a highly similar factorial structure in the general population, with latent factors resembling the classical schizophrenia positive, negative, and disorganization symptom dimensions $[8,21-23]$. Much research has been done on the number of factors as well as the extent to which they are correlated. The consensus from primarily US studies centers around both a three-factor structure [22] and a four-factor structure [24, 25]. The few studies examining a four-factor structure [2426] support Stefanis et al. model with the factors Paranoid, Interpersonal, Cognitive-Perceptual, and Disorganization. For the three-factor models, the most commonly used factor labels are Cognitive-Perceptual, Interpersonal-Affective, and Disorganization (or Positive Schizotypy, Negative Schizotypy, and Disorganization). Ericson et al. [27] state that a threefactor structure has been replicated in at least 14 independent adult samples, across several populations, and in samples of both schizophrenic in patients and outpatients; for an overview of different type of models, see [26]. This indicates that a three-factor structure is a dominant and leading model for the clustering of schizotypal traits.

Considering the potential contribution in understanding neurodevelopmental mechanisms underlying schizotypal traits over the course of development (preceding the typical age of onset of schizophrenia spectrum disorders), there is a need for developing instruments measuring schizotypal traits in children and adolescents. Regarding the SPQ, there is a brief 22-item version for children 11 years and older (SPQC) [27], of which the factorial structure parallels those found in older and clinical groups. However, there is no full 74item version of the SPQ for children and adolescents, which would allow the measurement of specific schizotypal traits on subscale level.

Given the need for early identification of specific schizotypal traits in children, a children's version of the Schizotypal Personality Questionnaire was developed by adapting the original full 74-item adult SPQ [28]. As part of the validation of psychometric instruments assessing schizotypal traits comes from the dimensional structure of schizotypal traits, the aim of the present study was to evaluate the SPQ-C-D in Dutch children between 9 and 18 years old in terms of reliability and factor structure and to compare it with similar information from the original SPQ data by [8] and SPQ data from young adult participants in a study by Compton et al. [24].

\section{Materials and Methods}

2.1. Participants. The SPQ was completed by 219 children and adolescents (106 girls and 113 boys). Age ranged from 9 to 18 years, with a mean age of 11.8 years ( $\mathrm{sd} 2.4)$. The period of data collection was between 2003 and 2011. Children were recruited from ten mainstream schools distributed across the western half of Netherlands. All children were screened for psychopathology, with none of the included participants scoring in the clinical range $(>70)$ on the Childhood Behavior Checklist (CBCL) [29]. After providing a complete description of the study to the subjects and to their parents, we obtained written informed consent according to the Declaration of Helsinki. The study was approved by the ethical committees of Leiden University Medical Center and the University Medical Center Utrecht.

2.2. Instruments. All subjects completed the children's version of the Schizotypal Personality Questionnaire (SPQ) [8], originally translated into Dutch and validated for adults by Vollema et al. $[23,28,30]$. Adaptations to the Dutch SPQ version for children were done (in consensus) by the authors who are working in the field of developmental neuropsychology. Such an expert committee is needed to "achieve four types of equivalence: semantic (i.e., equivalence in meaning of words), idiomatic (i.e., equivalent expressions have to be found or items have to be substituted), experiential (i.e., the situation evoked or depicted in the source version should fit the target cultural context), and conceptual (i.e., is the concept explored valid in the target culture?)" [31]. The expert committee made such minor adaptations, which involved a change in using simpler expressions rather than complex expressions to accommodate a younger age group. In some of the questions developmentally specific words such as "work" were replaced with "school" and "writing letters" was changed to "texting and sending emails" to place the questions in an appropriate context. For all items. The SPQ-C-D is a 74-item questionnaire with a dichotomous response format (applies to me, does not apply to me), with a total score ranging from 0 to 74 .

\subsection{Statistical Methods}

2.3.1. Reliability: Internal Consistency. Given that previous studies used Cronbach's alpha to establish the internal consistency of the subscales, we compared Cronbach's alphas of the subscales of the SPQ-C-D with those of the subscales published by Raine [32] and Compton et al. [24].

2.3.2. Factorial Structure. The analyses on our data and those by Compton et al. [24] were carried out with SPSS19 using an oblimin rotation. Unfortunately no other principal component outcomes were available for comparison with the literature.

Most published analyses of the SPQ are carried out via a confirmatory factor analysis but we decided to first perform a principal component analysis with an oblique rotation in order not to prejudice the solution of the three factors towards already existing solutions. The results were compared with the outcomes of data from Compton et al. [24] who kindly supplied us with their data set on undergraduates filling out Raine's standard SPQ. Subsequently, we compared our EQS 
TABLE 1: Internal consistencies of SPQ-C-D, Compton et al. [24] sample and Raine's [8] samples.

\begin{tabular}{|c|c|c|c|c|c|}
\hline Subscale names & Items in subscales & $\begin{array}{l}\text { SPQ-C-D } \\
\quad \alpha\end{array}$ & $\begin{array}{c}\text { Compton } \\
\alpha\end{array}$ & $\begin{array}{c}\text { Raine } \\
\alpha\end{array}$ & $N$ items \\
\hline \multicolumn{6}{|c|}{ Interpersonal } \\
\hline Social Anxiety & $\begin{array}{c}\text { Item } 2 \text {, item } 11 \text {, item } 20 \text {, item } 29 \text {, item } 38 \text {, item } 46 \text {, } \\
\text { item } 54 \text {, item } 71\end{array}$ & .73 & .79 & $.72, .88$ & 8 \\
\hline Constricted Affect & $\begin{array}{l}\text { Item } 8 \text {, item } 17 \text {, item } 26 \text {, item } 35 \text {, item } 43 \text {, item } 51 \text {, } \\
\text { item } 68 \text {, item } 73\end{array}$ & .56 & .71 & $.66, .65$ & 8 \\
\hline No Close Friends & $\begin{array}{c}\text { Item } 6 \text {, item } 15 \text {, item } 24 \text {, item } 33 \text {, item } 41 \text {, item } 49 \text {, } \\
\text { item } 57 \text {, item } 62 \text {, item } 66\end{array}$ & .48 & .75 & $.67, .74$ & 9 \\
\hline \multicolumn{6}{|c|}{ Cognitive/Perceptual } \\
\hline $\begin{array}{l}\text { Unusual Perceptual } \\
\text { (Experiences) }\end{array}$ & $\begin{array}{c}\text { Item } 4 \text {, item } 13 \text {, item } 22 \text {, item } 31 \text {, item } 40 \text {, item } 48 \text {, } \\
\text { item } 56 \text {, item } 61 \text {, item } 64\end{array}$ & .78 & .73 & $.71, .73$ & 9 \\
\hline $\begin{array}{l}\text { (Suspiciousness/Paranoid } \\
\text { Ideation) Paranoia }\end{array}$ & $\begin{array}{c}\text { Item } 9 \text {, item } 18 \text {, item } 27 \text {, item } 36 \text {, item } 44 \text {, item } 52 \text {, } \\
\text { item } 59 \text {, item } 6\end{array}$ & .73 & .75 & $.78, .73$ & 8 \\
\hline Ideas of Reference & $\begin{array}{c}\text { Item } 1 \text {, item } 10 \text {, item } 19 \text {, item } 28 \text {, item } 37 \text {, item } 45 \text {, } \\
\text { item } 53 \text {, item } 60 \text {, item } 63\end{array}$ & .72 & .74 & $.71, .71$ & 9 \\
\hline $\begin{array}{l}\text { (Odd Beliefs/)Magical } \\
\text { Thinking }\end{array}$ & $\begin{array}{l}\text { Item } 3 \text {, item } 12 \text {, item } 21 \text {, item } 30 \text {, item } 39 \text {, item } 47, \\
\text { item } 55\end{array}$ & .67 & .70 & $.81, .75$ & 7 \\
\hline \multicolumn{6}{|c|}{ Disorganization } \\
\hline Eccentric(/Odd) Behaviour & $\begin{array}{c}\text { Item } 5 \text {, item } 14 \text {, item } 23 \text {, item } 32 \text {, item } 67 \text {, item } 70 \text {, } \\
\text { item } 74\end{array}$ & .77 & .83 & $.78, .74$ & 7 \\
\hline Odd Speech & $\begin{array}{c}\text { Item } 7 \text {, item } 16 \text {, item } 25 \text {, item } 34 \text {, item } 42 \text {, item } 50 \text {, } \\
\text { item } 58 \text {, item } 69 \text {, item } 72\end{array}$ & .74 & .77 & $.70, .74$ & 9 \\
\hline Interpersonal & & .84 & .89 & & 25 \\
\hline Cognitive/Perceptual & & .89 & .88 & & 33 \\
\hline Disorganization & & .82 & .86 & & 16 \\
\hline $\begin{array}{l}\text { Total scale } \\
\text { (based on } 9 \text { subscales) }\end{array}$ & & .85 & .87 & & 9 \\
\hline $\begin{array}{l}\text { Total scale } \\
\text { (based on } 74 \text { items) }\end{array}$ & & .92 & .94 & $.91, .90$ & 74 \\
\hline
\end{tabular}

confirmatory factor analysis results with those analyses available from the literature.

2.3.3. Effects of Age and Sex. Based on the reliabilities and factorial analyses that are part of this study, we analyzed the effects of age and sex for three SPQ domains as well as the total SPQ score. The age distribution of our sample is such that in order to get sufficient persons in a group for reliable estimates we grouped the 13- and 14-year-olds, and the 15-, 16-, 17+year-olds. Only cases with scores on all items were included.

\section{Results}

3.1. Reliability: Internal Consistency. First, with respect to the three domain scores and the total score, all reliabilities were larger than .82. They were very similar to the Compton et al. ones (Raine's domain score reliabilities were not available). The subscale reliability analysis showed that the subscales have comparable Cronbach's $\alpha$ 's to Raine's and Compton et al. samples, except for relatively low $\alpha$ 's for the Interpersonal subscales, No Close Friends $(\alpha=.47)$, and Constricted Affect ( $\alpha=.56)$ as well as Magical Thinking $(\alpha=.67)$ in our study. Note that the No Close Friends and Constricted Affect were also borderline in the Raine samples but fully acceptable for the Compton et al. sample. See Table 1 for all Cronbach's $\alpha$ 's.

\subsection{Factorial Structure}

3.2.1. Principal Component Analysis. In our evaluation of the SPQ-C-D we restricted analysis to a three-factor structure with an oblique rotation. The comparison between the SPQ$\mathrm{C}-\mathrm{D}$ and the Compton et al. results shows both agreement and some differences with respect to which subscale belongs to which component. All results are presented in Table 2 and the items in the outlined text boxes indicate Raine's structure of the original SPQ. Results show that the pattern of subscales loading on the three components of the SPQ-C-D resembles closely the pattern of Raine's confirmatory factor analyses. Different from Raine's original construction, in our study Constricted Affect loaded on two components, that is, Interpersonal and Disorganization. Dissimilarities with Raine's solution were also emphasised by Compton et al. who concluded after carrying out a confirmatory factor analysis that their data conformed more with the Stefanis et al. fourfactor model than with Raine's three-factor model. It is interesting to note that the correlations between the components were very similar in both studies. 
TABLE 2: Factorial structure of the SPQ-C-D and Compton et al. [24] sample: three-component solution based on subscales.

(a) Pattern matrix SPQ-C-D

\begin{tabular}{|c|c|c|c|}
\hline & \multicolumn{3}{|c|}{ Component } \\
\hline & $\begin{array}{l}\text { Cognitive/ } \\
\text { Perceptual }\end{array}$ & Interpersonal & Disorganization \\
\hline Ideas of Reference & $.66^{*}$ & & .21 \\
\hline Magical Thinking & $.95^{*}$ & & -.15 \\
\hline $\begin{array}{l}\text { Unusual Perceptual } \\
\text { Experiences }\end{array}$ & $.79^{*}$ & & .18 \\
\hline Paranoid Ideation & $.47^{*}$ & $.34^{*}$ & .29 \\
\hline Social Anxiety & .16 & $.89^{*}$ & -.22 \\
\hline No Close Friends & & $.75^{*}$ & .27 \\
\hline Constricted Affect & & $.47^{*}$ & .53 \\
\hline $\begin{array}{l}\text { Eccentric } \\
\text { Behaviour }\end{array}$ & .15 & & $.78^{*}$ \\
\hline Odd Speech & & & $.77^{*}$ \\
\hline \multicolumn{4}{|c|}{ Component correlation matrix } \\
\hline Component & $\mathrm{CP}$ & IP & DO \\
\hline $\mathrm{CP}$ & 1.00 & .38 & .38 \\
\hline IP & .38 & 1.00 & .31 \\
\hline DO & .38 & .31 & 1.00 \\
\hline
\end{tabular}

Rotation method: oblimin with Kaiser normalization.

Alphas $<.15$ are not presented. Bold: subscale loads on component. Data with “*”: factorial structure Raine.

CP: Cognitive Perceptual, IP: Interpersonal, and DO: Disorganization.

(b) Pattern matrix Compton et al. study

\begin{tabular}{|c|c|c|c|}
\hline & \multicolumn{3}{|c|}{ Component } \\
\hline & $\begin{array}{l}\text { Cognitive/ } \\
\text { Perceptual }\end{array}$ & Interpersonal & Disorganization \\
\hline Ideas of Reference & $.82^{*}$ & & .20 \\
\hline Magical Thinking & $.18^{*}$ & -.21 & .79 \\
\hline $\begin{array}{l}\text { Unusual Perceptual } \\
\text { Experiences }\end{array}$ & $.29^{*}$ & & .72 \\
\hline Paranoid Ideation & $.68^{*}$ & $.37^{*}$ & \\
\hline No Close Friends & & $.85^{*}$ & \\
\hline Social Anxiety & -.26 & $.75^{*}$ & \\
\hline Constricted Affect & & $.82^{*}$ & .17 \\
\hline $\begin{array}{l}\text { Eccentric } \\
\text { Behaviour }\end{array}$ & -.17 & .29 & $.75^{*}$ \\
\hline Odd Speech & & .41 & $.58^{*}$ \\
\hline \multicolumn{4}{|c|}{ Component correlation matrix } \\
\hline Component & $\mathrm{CP}$ & IP & DO \\
\hline $\mathrm{CP}$ & 1.00 & .29 & .36 \\
\hline IP & .29 & 1.00 & .33 \\
\hline DO & .36 & .33 & 1.00 \\
\hline
\end{tabular}

Rotation Method: Oblimin with Kaiser normalization.

Alphas $<.15$ are not presented. Bold: subscale loads on component. CP: Cognitive Perceptual, IP: Interpersonal, and DO: Disorganization.
3.3. Confirmatory Factor Analysis. To compare the structure of our questionnaire in more detail with that of Raine et al.'s [22] US sample we performed a confirmatory factor analysis on our data taking as our starting point Raine et al's [22] solutions for their undergraduate and their community samples (see right-hand panel of Table 3). Given the large coefficient for Constricted Affect on the Disorganization component solution we tested whether it was necessary to include this regression coefficient in the basic confirmatory factor analysis, but this turned out not to be necessary. In Table 3 we have given an overview of several models fitted, including Compton et al's favoured three-factor model. In sum, a threefactor model with an additional path from the Disorganization factor to Unusual Perceptual Experiences but especially a correlated error term between Unusual Perceptual Experiences and Magical Thinking was needed to get an adequate model fit. Moreover, for the SPQ-C-D, Compton et al.s adaption was not necessary. For an overview of the factor loadings see Table 4 .

\subsection{Properties of the Total Score and Three Domain Scores}

3.4.1. Distribution. The distributions of the total score and three dimensions showed a positive skew with a lower bound of 0 , indicating that high scores are relatively rare. Furthermore, there were several subjects with outlying score on two of the domains, but none of them on all three domains. Although there were some outliers for all variables, there were virtually no extreme scores.

3.4.2. Effects of Age and Sex. We found no significant differences in mean scores between boys and girls, and there were no significant differences in mean scores between the age groups; see Table 5 for means and standard deviations. Average total score in our 9-18-year-old sample (16.3) was significantly lower than the average total score in the young adult sample in the Compton et al. study (23.2), $t=6.8, \mathrm{df}=974$; $P<.001$; Cohen's $d=54$ (see Table 5).

\section{Conclusion}

The aim of the present study was to evaluate the 74-item Schizotypal Personality Questionnaire adapted for Dutch children between 9 and 18 years old (SPQ-C-D). It was evaluated in terms of reliability, factor structure, and distribution of scores and compared to the original SPQ data by Raine [8] and another study with young adult participants.

First, reliability in terms of internal consistency was assessed. As for the total score and the three domain scores (Interpersonal, Cognitive-Perceptual, and Disorganization) reliabilities were between 0.82 and 0.92 . Therefore, the SPQ$\mathrm{C}-\mathrm{D}$ is a reliable instrument for assessing schizotypal traits in children using these dimensions. The three domains were correlated, similar to what is found in other studies, which may point to one single underlying factor conveying overall level of schizotypal traits. Regarding reliability of the nine individual subscales, most showed good reliability with $\alpha$ ranging from 0.72 to 0.78 . Similar to the other studies on adult 
TABLE 3: Model fit of Raine et al. and Compton et al. based on confirmatory factor analyses.

\begin{tabular}{|c|c|c|c|c|c|c|c|}
\hline Models & $\chi^{2}$ & $\mathrm{df}$ & $\chi^{2} / \mathrm{df}$ & Comparative fit index (CFI) & RMSEA & RMSEA interval & AIC \\
\hline \multicolumn{8}{|l|}{ Raine et al. [22], three-factor model } \\
\hline Base & 81.9 & 23 & 3.56 & .92 & .11 & $.08-.14$ & 35.9 \\
\hline$+r(\mathrm{MT}, \mathrm{UPE})$ & 48.7 & 22 & 2.21 & .96 & .08 & $.05-.10$ & 4.7 \\
\hline$+(\mathrm{DO} \rightarrow \mathrm{UPE})$ and $r(\mathrm{MT}, \mathrm{UPE})$ & 26.7 & 21 & 1.27 & .99 & .04 & $.00-.07$ & -15.3 \\
\hline \multicolumn{8}{|l|}{ Compton et al. [24], three-factor model } \\
\hline Base & 46.9 & 20 & 2.35 & .96 & .08 & $.05-.11$ & 6.9 \\
\hline$-\mathrm{CP} \rightarrow$ SocAnx & 48.1 & 21 & 2.29 & .96 & .08 & $.05-.11$ & 6.2 \\
\hline
\end{tabular}

Note: for the confirmatory factor analysis 6 children were excluded because of their large contribution to the multivariate kurtosis, while five children were excluded because they did not have complete data on all of the subscales. RMSEA = root mean square error of approximation; AIC $=$ Akaike information criterion, and $\mathrm{df}=$ degrees of freedom. $r(\mathrm{MT}, \mathrm{UPE})=$ correlated error between Magical Thinking and Unusual Perceptual Experiences; DO $\rightarrow$ UPE $=$ path between the Disorganization component and Unusual Perceptual Experiences. CP $\rightarrow$ Social Anxiety $=$ path between the Cognitive/Perceptual Component and Social Anxiety.

populations, there were relatively low $\alpha$ 's for the subscales "No Close Friends" ( $\alpha=.47)$, "Constricted Affect" ( $\alpha=.56)$, and "Magical Thinking" ( $\alpha=.67)$. Overall, given the differences in samples and the translation steps, there is a high degree of agreement in reliabilities between the SPQ-C-D and the other two studies, that is, samples of Raine et al. [22] and Compton et al. [24]. Thus, the SPQ-C-D can also be reliably used for assessing specific types of schizotypal traits.

Second, we explored the factorial structure of the SPQ-C-D by using principal component analysis (PCA). PCA showed that "Ideas of Reference," "Magical Thinking," "Unusual Perceptual Experiences," and "Paranoid Ideation" loaded on one component, identical to the CognitivePerceptual component in the original study by Raine. Furthermore, "Paranoid Ideation," "Social Anxiety," "No Close Friends," and "Constricted Affect" loaded on one component, identical to the Interpersonal component in the original study by Raine. Finally, again similar to the Raine study, "Eccentric Behavior" and "Odd Speech" contributed to one component, that is, Disorganization. Here, one difference with the original Raine study was that Constricted Affect also loaded on this component in our study. The components in our study also resembled those of the Compton et al. study, except for some small variations. Two out of four subscales that load on Cognitive-Perceptual component in the Raine study loaded on Disorganization in the Compton et al. study. In addition, Odd Speech loaded not only on Disorganization, but also on the Interpersonal component in the Compton et al. study. Thus, slight variations in loading of subscales to components have been found in several other studies with the original instrument and are not specific to our study. Nonetheless, the high loading of "Constricted Affect" on the Disorganization component in our study needs replication in future studies.

Third, in order to more thoroughly test if data collected with the SPQ-C-D fit the factorial structure of the original study by Raine et al. [22], we used confirmatory factor analysis. Forcing Raine's factorial structure on our data resulted in an adequate model fit with the presence of a correlated error term between Unusual Perceptual Experiences and Magical Thinking and an additional path from the Disorganization factor to Unusual Perceptual Experiences. Taken together, comparing factorial structure using both explorative techniques, that is, principal component analysis, and model fit techniques, that is, confirmatory factor analyses, showed that the factorial structure of the SPQ-C-D is very similar to that in the original Raine study and that the degree of variation was similar to the degree of variation found in other samples using Raine's original version of the SPQ.

\section{Discussion}

Although analysis of the factorial structure indicated adequate properties of the SPQ-C-D, it is important to discuss factors that should be taken into account. In terms of distribution of the mean SPQ-C-D scores, this was somewhat skewed with most scores on the lower end as could be expected in a nonclinical sample. However, considering the large sample size, this did not have a negative effect on analyses of the reliability and factorial structure of the SPQ-C-D. There were no differences between boys and girls, and there was no effect of age on mean scores. The mean number of affirmative responses ("applies to me") on item level was overall lower in our study as compared to the Compton et al. [24] undergraduate study, particularly for items in the CognitivePerceptual domain. This may have several implications. First, if there are any effects of variation in interpretation of the questions and level of self-reflection in this relatively young group, that is, 9 to 18 years old, any bias that would result from this would be in the direction of underreporting rather than overreporting schizotypal traits according to our findings. Second, although differences in number of affirmative responses might be due to interpretation factors, it could also be related to developmental effects, with the younger group (9 to 18 years old) in our study having significantly lower levels of schizotypal traits as compared to the young adult group in the study by Compton et al. [24], who are more close to the typical peak age of onset of psychotic disorders [33]. However, this is in contrast to findings from meta-analysis of developmental dynamics of psychotic symptoms, which has shown higher rates in children as compared to adolescents and adults and a decline of the incidence of psychotic symptoms over 
TABLE 4: Confirmatory factor analysis: the three-factor solution based on subscales for the SPQ-C-D and Raine's samples.

(a) SPQ-C-D study

\section{Component}

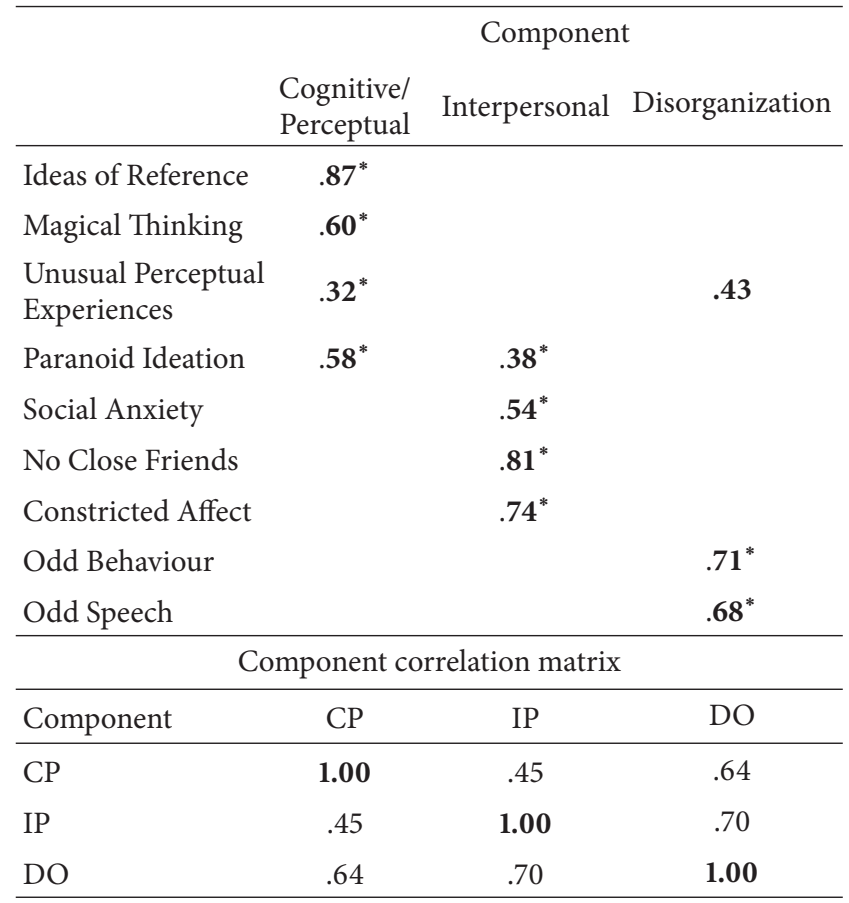

$R(\mathrm{UPE}, \mathrm{MT})$

.55

Alphas $<.15$ are not presented. Bold: subscale loads on component. Data with “*”: factorial structure Raine. CP: Cognitive Perceptual, IP: Interpersonal, and DO: Disorganization.

(b) Raine et al. [22]: undergraduate sample (left); community sample (right)

\section{Component}

Cognitive/ Perceptual

Interpersonal Disorganization

\begin{tabular}{|c|c|c|c|}
\hline Ideas of Reference & $.75 / .83^{*}$ & & \\
\hline Magical Thinking & $.62 / .53^{*}$ & & \\
\hline $\begin{array}{l}\text { Unusual Perceptual } \\
\text { Experiences }\end{array}$ & $.78 / .74^{*}$ & & \\
\hline Paranoid Ideation & $.47 / .56^{*}$ & $.45 / .41^{*}$ & \\
\hline Social Anxiety & & $.58 / .66^{*}$ & \\
\hline No Close Friends & & $.77 / .89^{*}$ & \\
\hline Constricted Affect & & $.76 / .81^{*}$ & \\
\hline Odd Behaviour & & & $.62 / .49^{*}$ \\
\hline Odd Speech & & & $.74 / .88^{*}$ \\
\hline \multicolumn{4}{|c|}{ Component correlation matrix } \\
\hline Component & $\mathrm{CP}$ & IP & DO \\
\hline $\mathrm{CP}$ & 1.00 & $.20 / .37$ & $.71 / .75$ \\
\hline IP & $.20 / .37$ & 1.00 & $.44 / .60$ \\
\hline DO & $.71 / .75$ & $.44 / .60$ & 1.00 \\
\hline
\end{tabular}

Alphas <.15 are not presented. Bold: subscale loads on component. Data with “*”: factorial structure Raine. CP: Cognitive Perceptual, IP: Interpersonal, and DO: Disorganization. time $[6,33,34]$. This has led some to speculate that "early adult neurodevelopmental processes (e.g., increased myelination of white matter, gray matter loss) or changes in social circumstances (e.g., marriage, transition from school to employment) may give clues as to factors that ameliorate and even protect against schizotypal personality disorder" [33]. Unfortunately, the cross-sectional comparisons in our study do not allow drawing firm conclusions about developmental dynamics of schizotypal traits as measured with the SPQ.

There are some limitations of this study that should be noted. First, we only assessed reliability and factorial structure of the SPQ-C-D in a nonclinical sample. Inclusion of clinical groups would have provided stronger empirical support and would have allowed us to investigate if and how the SPQ-C-D could be used in clinical context. Second, we did not have a longitudinal design. This prevented us from assessing test-retest reliability. This also did not allow us to test to what degree scores on the SPQ-C-D are predictive of psychopathology later in development. Third, as some of the subscales showed relatively low reliability, interpretation of these subscales should occur with caution, especially on the level of individual assessment. Fourth, we cannot exclude that translation issues and age differences between our study and others may have added "noise" to the data. However, in spite of this added variation, a factorial structure that is very similar to the original SPQ was found, implying that the SPQ-C-D is valid in spite of these potential issues.

In the future, it would be interesting to consider Likert rating scales with five scale points ranging from 0 (strong disagree) to 4 (strongly agree), as has been done in other studies, for example, Wuthrich and Bates [26], to add an even more robust and sensitive evaluation of levels of traits. Notwithstanding we have decided to follow the original questionnaire and use binary items to stay in line with previous research; a detailed study of comparing the effectiveness of both types of items is warranted. Also, it would be interesting to use the SPQ-C-D in a longitudinal design, such as a tenyear follow-up of the sample in this study, which allows assessment of the predictive value of schizotypy scores for level of psychopathology in early adulthood.

\section{Conflict of Interests}

The authors declare that there is no conflict of interests regarding the publication of this paper.

\section{Acknowledgments}

The authors are very grateful to Michael Compton and Erin Brooke Tone for providing them with their data, which enabled them to carry out the comparisons reported in this paper. They thank Marit Bierman for help with adapting the SPQ questionnaire. This work was supported by a personal grant (Grant no. 016.095.060) to Sophie van Rijn from the Netherlands Organization for Scientific Research (NWO). 
TABLE 5: Total score and domain scores for the different age groups.

\begin{tabular}{|c|c|c|c|c|c|c|c|c|c|}
\hline \multirow{2}{*}{ Age group } & \multicolumn{3}{|c|}{ Total Score } & \multicolumn{2}{|c|}{ Interpersonal } & \multicolumn{2}{|c|}{ Cognitive/Perceptual } & \multicolumn{2}{|c|}{ Disorganization } \\
\hline & $N$ & M & sd & $\mathrm{M}$ & sd & $\mathrm{M}$ & sd & M & sd \\
\hline 9 & 39 & 16.7 & 9.2 & 8.3 & 4.2 & 6.5 & 5.4 & 3.4 & 3.1 \\
\hline 10 & 45 & 19.2 & 12.9 & 8.6 & 6.2 & 7.6 & 7.3 & 4.7 & 3.5 \\
\hline 11 & 39 & 16.6 & 12.1 & 7.5 & 5.0 & 6.2 & 6.6 & 4.3 & 3.6 \\
\hline 12 & 36 & 15.5 & 11.6 & 6.5 & 5.2 & 5.6 & 5.7 & 4.7 & 3.7 \\
\hline $13+14$ & 27 & 15.2 & 11.0 & 6.6 & 5.5 & 6.4 & 5.3 & 3.9 & 3.7 \\
\hline 15-18 & 33 & 13.2 & 10.2 & 5.3 & 4.9 & 5.5 & 5.6 & 3.6 & 3.6 \\
\hline Total & 219 & 16.3 & 11.4 & 7.3 & 5.3 & 6.4 & 6.1 & 4.2 & 3.5 \\
\hline $\begin{array}{l}\text { Compton et } \\
\text { al. [24] }\end{array}$ & 757 & 23.2 & 13.7 & 10.2 & 7.0 & 10.5 & 6.7 & 5.3 & 4.1 \\
\hline$t$-value & & 6.8 & & 5.7 & & 8.1 & & 3.6 & \\
\hline Effect size $(d)$ & & .54 & & .46 & & .64 & & .29 & \\
\hline
\end{tabular}

Notes: $\mathrm{df}=974 ;$ all $P$ values $<.001$.

\section{References}

[1] R. J. Linscott and J. van Os, "Systematic reviews of categorical versus continuum models in psychosis: evidence for discontinuous subpopulations underlying a psychometric continuum. Implications for DSM-V, DSM-VI, and DSM-VII," in Annual Review of Clinical Psychology, S. Nolen-Hoeksema, T. D. Cannon, and T. Widiger, Eds., vol. 6, pp. 391-419, Annual Reviews, Palo Alto, Calif, USA, 2010.

[2] R. Mullen, "Delusions: the continuum versus category debate," Australian and New Zealand Journal of Psychiatry, vol. 37, no. 5, pp. 505-511, 2003.

[3] J. P. Chapman, L. J. Chapman, and T. R. Kwapil, "Scales for the measurement of schizotypy," in Schizotypal Personality, A. Raine, T. Lencz, and S. A. Mednick, Eds., Cambridge University Press, New York, NY, USA, 1995.

[4] G. Claridge, Schizotypy: Implications for Illness and Health, Oxford University Press, Oxford, UK, 1997.

[5] P. E. Meehl, "Schizotaxia revisited," Archives of General Psychiatry, vol. 46, no. 10, pp. 935-944, 1989.

[6] J. van Os, R. J. Linscott, I. Myin-Germeys, P. Delespaul, and L. Krabbendam, "A systematic review and meta-analysis of the psychosis continuum: evidence for a psychosis pronenesspersistence-impairment model of psychotic disorder," Psychological Medicine, vol. 39, no. 2, pp. 179-195, 2009.

[7] A. R. Yung, H. P. Yuen, L. J. Phillips, S. Francey, and P. D. McGorry, "Mapping the onset of psychosis: the comprehensive assessment of at risk mental states (CAARMS)," Schizophrenia Research, vol. 60, no. 1, pp. 30-31, 2003.

[8] A. Raine, “The SPQ: a scale for the assessment of schizotypal personality based on DSM-III-R criteria," Schizophrenia Bulletin, vol. 17, no. 4, pp. 555-564, 1991.

[9] A. Raine and D. Benishay, "The SPQ-B: a brief screening instrument for schizotypal personality disorder," Journal of Personality Disorders, vol. 9, no. 4, pp. 346-355, 1995.

[10] T. J. Crow, D. J. Done, and A. Sacker, "Childhood precursors of psychosis as clues to its evolutionary origins," European Archives of Psychiatry and Clinical Neuroscience, vol. 245, no. 2, pp. 61-69, 1995.

[11] M. Isohanni, P. Jones, L. Kemppainen et al., "Childhood and adolescent predictors of schizophrenia in the Northern Finland
1966 Birth Cohort-a descriptive life-span model," European Archives of Psychiatry and Clinical Neuroscience, vol. 250, no. 6, pp. 311-319, 2000.

[12] A. Reichenberg, A. Caspi, H. Harrington et al., "Static and dynamic cognitive deficits in childhood preceding adult schizophrenia: a 30-year study," The American Journal of Psychiatry, vol. 167, no. 2, pp. 160-169, 2010.

[13] E. Walker and A. M. Bollini, "Pubertal neurodevelopment and the emergence of psychotic symptoms," Schizophrenia Research, vol. 54, no. 1-2, pp. 17-23, 2002.

[14] N. Kaymaz, M. Drukker, R. Lieb et al., "Do subthreshold psychotic experiences predict clinical outcomes in unselected nonhelp-seeking population-based samples? A systematic review and meta-analysis, enriched with new results," Psychological Medicine, vol. 42, no. 11, pp. 2239-2253, 2012.

[15] T. R. Kwapil, "Social anhedonia as a predictor of the development of schizophrenia-spectrum disorders," Journal of Abnormal Psychology, vol. 107, no. 4, pp. 558-565, 1998.

[16] R. Poulton, A. Caspi, T. E. Moffitt, M. Cannon, R. Murray, and H. Harrington, "Children's self-reported psychotic symptoms and adult schizophreniform disorder: a 15-year longitudinal study," Archives of General Psychiatry, vol. 57, no. 11, pp. 10531058, 2000.

[17] W. Rössler, A. Riecher-Rössler, J. Angst et al., "Psychotic experiences in the general population: a twenty-year prospective community study," Schizophrenia Research, vol. 92, no. 1-3, pp. $1-14,2007$.

[18] L. J. Chapman, J. P. Chapman, T. R. Kwapil, M. Eckblad, and M. C. Zinser, "Putatively psychosis-prone subjects 10 years later," Journal of Abnormal Psychology, vol. 103, no. 2, pp. 171-183, 1994.

[19] D. C. Gooding, K. A. Tallent, and C. W. Matts, "Clinical status of at-risk individuals 5 years later: further validation of the psychometric high-risk strategy," Journal of Abnormal Psychology, vol. 114, no. 1, pp. 170-175, 2005.

[20] M. F. Lenzenweger, "Psychometric high-risk paradigm, perceptual aberrations, and schizotypy: an update," Schizophrenia Bulletin, vol. 20, no. 1, pp. 121-135, 1994.

[21] G. Claridge, C. McCreery, O. Mason et al., "The factor structure of 'schizotypal' traits: a large replication study," British Journal of Clinical Psychology, vol. 35, no. 1, pp. 103-115, 1996. 
[22] A. Raine, C. Reynolds, T. Lencz, A. Scerbo, N. Triphon, and D. Kim, "Cognitive-perceptual, interpersonal, and disorganized features of schizotypal personality," Schizophrenia Bulletin, vol. 20, no. 1, pp. 191-201, 1994.

[23] M. G. Vollema and R. J. van den Bosch, "The multidimensionality of schizotypy," Schizophrenia Bulletin, vol. 21, no. 1, pp. 19-31, 1995.

[24] M. T. Compton, S. M. Goulding, R. Bakeman, and E. B. McClure-Tone, "Confirmation of a four-factor structure of the Schizotypal Personality Questionnaire among undergraduate students," Schizophrenia Research, vol. 111, no. 1-3, pp. 46-52, 2009.

[25] N. C. Stefanis, N. Smyrnis, D. Avramopoulos, I. Evdokimidis, I. Ntzoufras, and C. N. Stefanis, "Factorial composition of selfrated schizotypal traits among young males undergoing military training," Schizophrenia Bulletin, vol. 30, no. 2, pp. 335-350, 2004.

[26] V. M. Wuthrich and T. C. Bates, "Confirmatory factor analysis of the three-factor structure of the Schizotypal Personality Questionnaire and Chapman schizotypy scales," Journal of Personality Assessment, vol. 87, no. 3, pp. 292-304, 2006.

[27] M. Ericson, C. Tuvblad, A. Raine, K. Young-Wolff, and L. A. Baker, "Heritability and longitudinal stability of schizotypal traits during adolescence," Behavior Genetics, vol. 41, no. 4, pp. 499-511, 2011.

[28] M. G. Vollema and H. Hoijtink, "The multidimensionality of self-report schizotypy in a psychiatric population: an analysis using multidimensional Rasch models," Schizophrenia Bulletin, vol. 26, no. 3, pp. 565-575, 2000.

[29] T. M. Achenbach, Manual for the Child Behaviour Checklist/418 and 1991 Profile, Department of Psychiatry, The University of Vermont, Burlington, Vt, USA, 1991.

[30] M. G. Vollema, M. M. Sitskoorn, M. C. M. Appels, and R. S. Kahn, "Does the Schizotypal Personality Questionnaire reflect the biological-genetic vulnerability to schizophrenia?" Schizophrenia Research, vol. 54, no. 1-2, pp. 39-45, 2002.

[31] C. Acquadro, K. Conway, A. Hareendran, and N. Aaronson, "Literature review of methods to translate health-related quality of life questionnaires for use in multinational clinical trials," Value in Health, vol. 11, no. 3, pp. 509-521, 2008.

[32] A. Raine, "The SPQ: a scale for the assessment of schizotypal personality based on DSM-III-R criteria," Schizophrenia Bulletin, vol. 17, no. 4, pp. 555-564, 1991.

[33] A. Raine, "Schizotypal personality: neurodevelopmental and psychosocial trajectories," Annual Review of Clinical Psychology, vol. 2, pp. 291-326, 2006.

[34] I. Kelleher, D. Connor, M. C. Clarke, N. Devlin, M. Harley, and M. Cannon, "Prevalence of psychotic symptoms in childhood and adolescence: a systematic review and meta-analysis of population-based studies," Psychological Medicine, vol. 42, no. 9, pp. 1857-1863, 2012. 


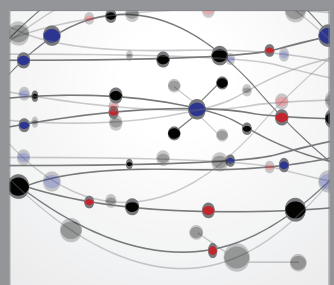

The Scientific World Journal
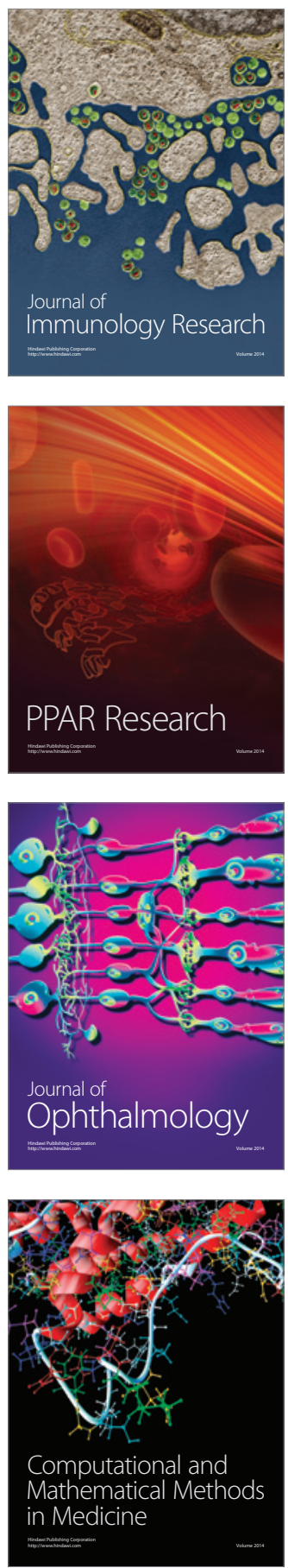

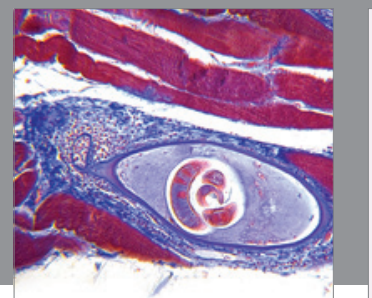

Gastroenterology

Research and Practice
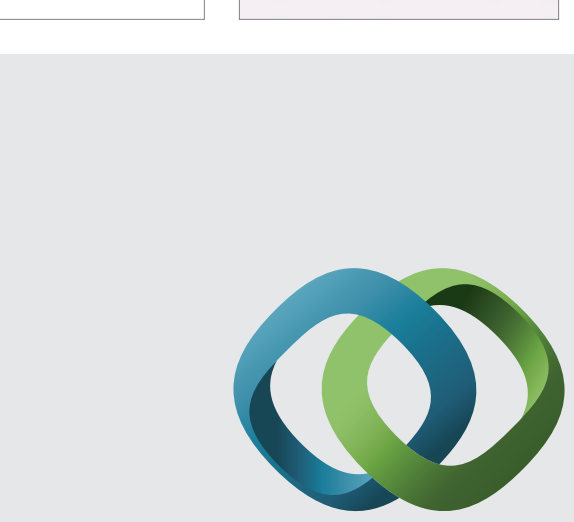

\section{Hindawi}

Submit your manuscripts at

http://www.hindawi.com
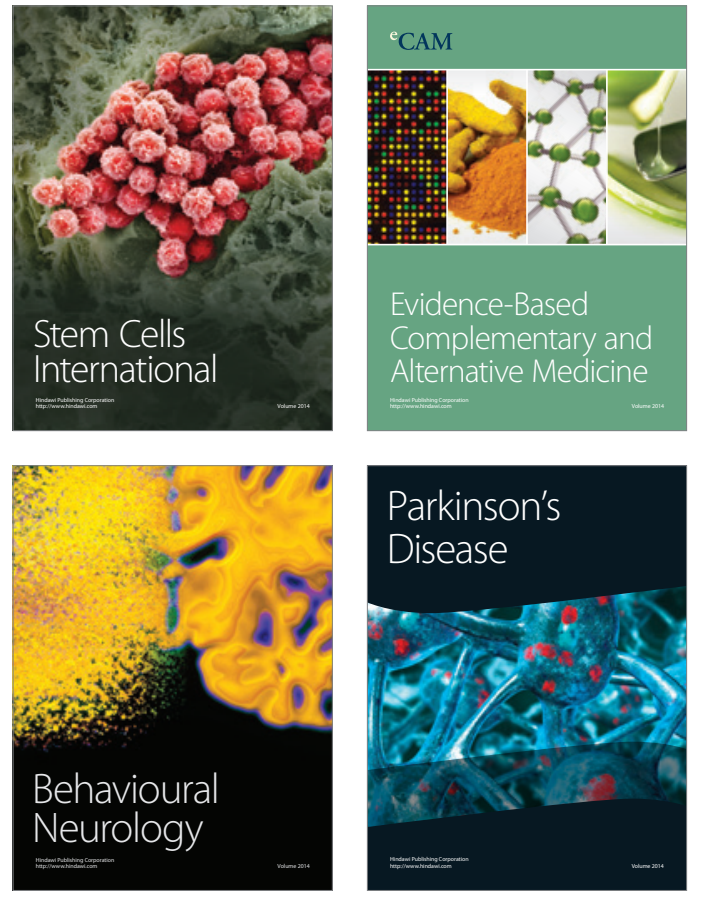
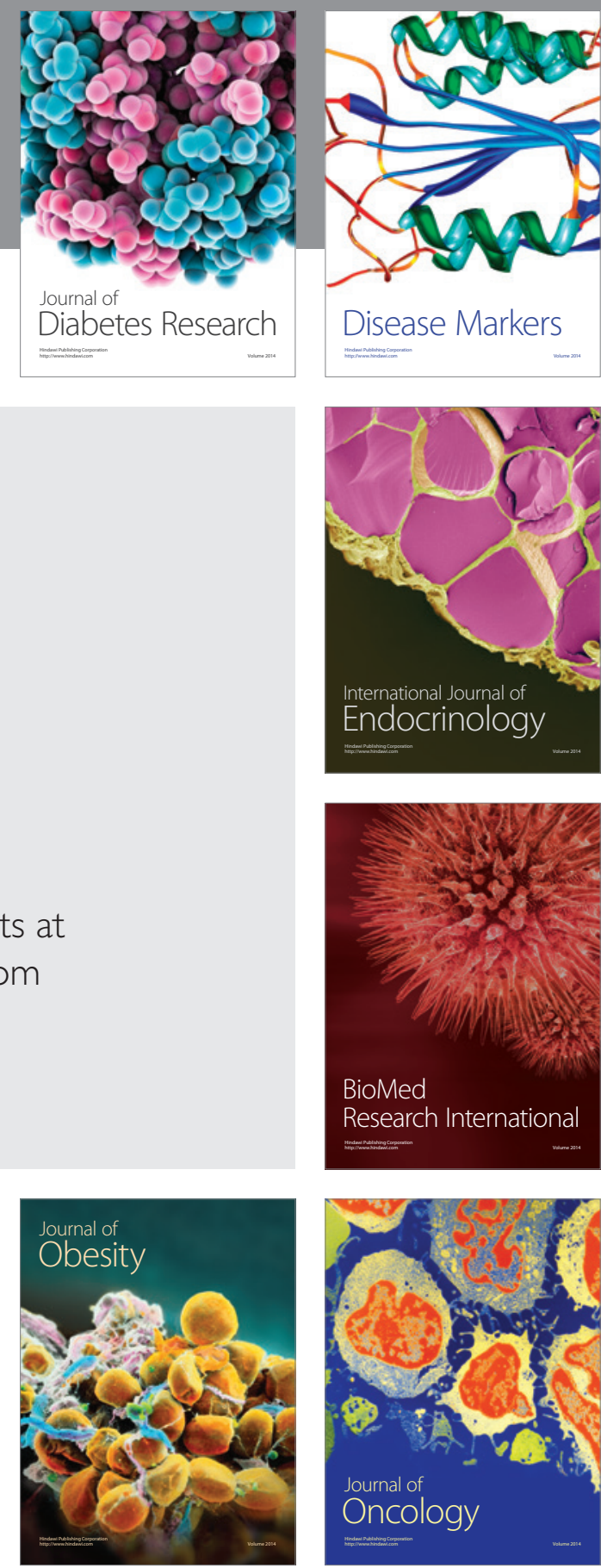

Disease Markers
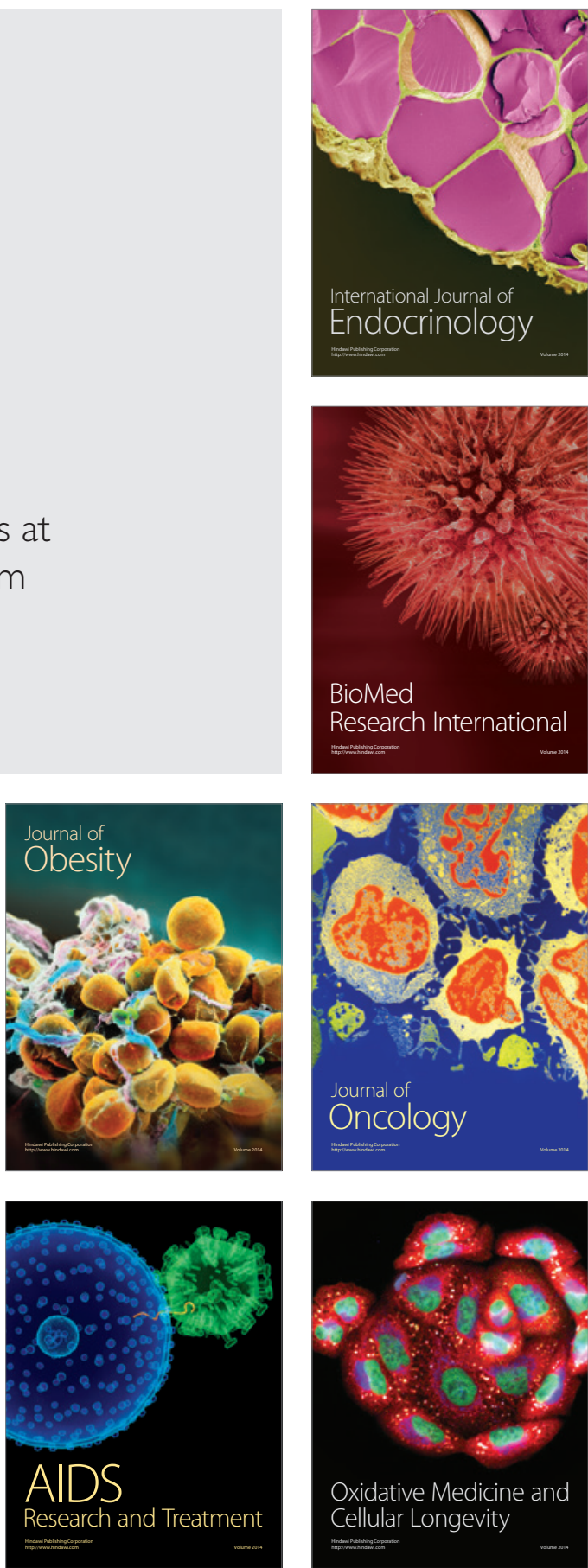